\title{
How can we translate advances in respiratory diseases into improved care?
}

\author{
Louis-Philippe Boulet MD FRCPC, President, Canadian Thoracic Society
}

$\mathrm{S}_{\mathrm{i}}^{\mathrm{i}}$ ince ancient times, the transmission of information of medical discoveries has always followed a similar process, although its speed has markedly increased in the past few years and means of communication have improved. On the other hand, the amount of information that becomes available to physicians and patients increases exponentially year after year, and this information comes from a variety of sources, some quite new and unregulated, such as Internet sites.

To help physicians cope with this huge amount of information, tools have been developed, such as medical reviews and updates in medical journals or other types of documents (eg, CD-ROMs such as the UpToDate Clinical Reference Library [UpToDate Inc, USA]), Internet sites and distribution materials. Therapeutic guidelines are now part of our environment, the most recent ones being 'evidence based'. Reference databases (eg, MEDLINE), specific sites and electronic mail systems (eg, Amedeo) perform regular reviews of the literature that are readily accessible on the Internet (this is not to forget continuing medical education [CME] initiatives, symposia and other meetings).

For patients, apart from the traditional and most appreciated sources of information (eg, physicians, pharmacists and other caregivers), information is increasingly available in the media and particularly on the Internet. Unfortunately, the quality of information is not always good, often conflicting or associated with commercial interests, and may sometimes antagonize valuable educational initiatives. It is often difficult for the patient (and even for caregivers) to have an idea of the validity of the sources involved.

Furthermore, despite these new modes of communication, there is still a significant 'care gap' between what is considered to be optimal care and what is currently available; this is considered to explain a large part of the persisting human and socioeconomic burden generated by many chronic diseases (1). Morbidity associated with many respiratory or other types of diseases, while often preventable, is indeed still high, and many deficiencies in respiratory care unfortunately persist. This may be related to a lack of resources or socioeconomic factors, but is often related to insufficient knowledge or to difficulties in integrating current understanding of the diseases to current care. For example, research done in Canada and the United States has shown that patients with asthma do not know the criteria used to evaluate asthma control, or that such control is still far from optimal (2). Furthermore, studies - including some done in Canada - have revealed that physicians' practices are not always in keeping with current guidelines (3). There is a need to help the public and physicians to acquire and integrate into care relevant and useful information to improve disease management, and to promote preventive measures $(4,5)$.

Societies, such as the Canadian Thoracic Society (CTS), have an important role in this regard, and initiatives such as consensus guidelines (and their implementation programs), collaboration on CME activities, symposia, publications and other means of communication (eg, Web sites) should be supported and tailored to current needs (Table 1). New ways to communicate should be developed, and new strategies to help medical practice and patient self-management should be tested. Ideally, messages to caregivers, patients and the public should be uniform to avoid confusion. In Canada, groups such as national or provincial disease-specific networks or associations can play an important role in providing a common 
TABLE 1

Some initiatives to help translate advances into care

Caregivers
Publications in medical and other journals
Presentations at national and international conferences
Discussion of recommendations at a local level
(with the participation of opinion leaders)
Web sites and educational materials
Mailings of key messages to physicians
Integration of recommendations to medical students' curriculum
Audit and feedback
Maintenance of certification programs
Interactive workshops
Aids to medical practice (eg, reminders, various tools and
materials, algorithms)
Disease management programs
National campaigns
Patients
Educational materials provided by various sources
Caregiver and specialized health educators interventions
Web sites and publications in the media
Disease management programs
Support groups
National campaigns

platform for different initiatives and for information sharing by stakeholders. The CTS and Canadian Lung Association are offering such a set-up, and are also participating in the activities of other groups, such as the Canadian Network For
Asthma Care and the Canadian Chronic Obstructive Pulmonary Disease Alliance. In regard to other actions originating from the CTS, it must be noted that the CTS' disease-specific committee has been increasingly active. New ways to update the current Canadian Asthma Consensus Guidelines, and to communicate with both caregivers and patients, are considered. The Education Committee has changed its name to the 'Professional Development Committee'. Its members, under the leadership of Drs Gordon Ford and Sharon Peters, have been very much involved in the development of the new 'Maintenance of Certification Program', and this group will provide accreditations and be a provider of professional activities recognized by the Royal College of Physicians and Surgeons of Canada. This will permit the CTS to provide accreditation for professional activities.

Hopefully, in collaboration with all of its partners, the CTS will help to develop new and more efficient ways of translating advances into care to improve the quality of life of Canadians.

\section{REFERENCES}

1. Weiss KB, Sullivan SD, Lyttle CS. Trends in the cost of illness for asthma in the United States, 1985-1994. J Allergy Clin Immunol 2000;106:493-9.

2. Asthma in Canada. A landmark survey. http://www.asthmaincanada.com. (Version current at March 12, 2001)

3. Jin R, Choi BCK, Chan BTB, et al. Physician asthma management practices in Canada. Can Respir J 2000;7:456-65.

4. Oxman AD, Thomson MA, Davis DA, Haynes RB. No magic bullets: a systematic review of 102 trials of interventions to improve professional practice. CMAJ 1995;153:1423-31.

5. Greco PJ, Eisenberg JM. Changing physicians' practices. N Engl J Med 1993;329:1271-4. 


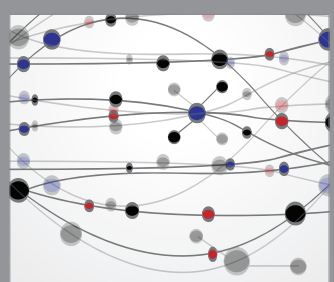

The Scientific World Journal
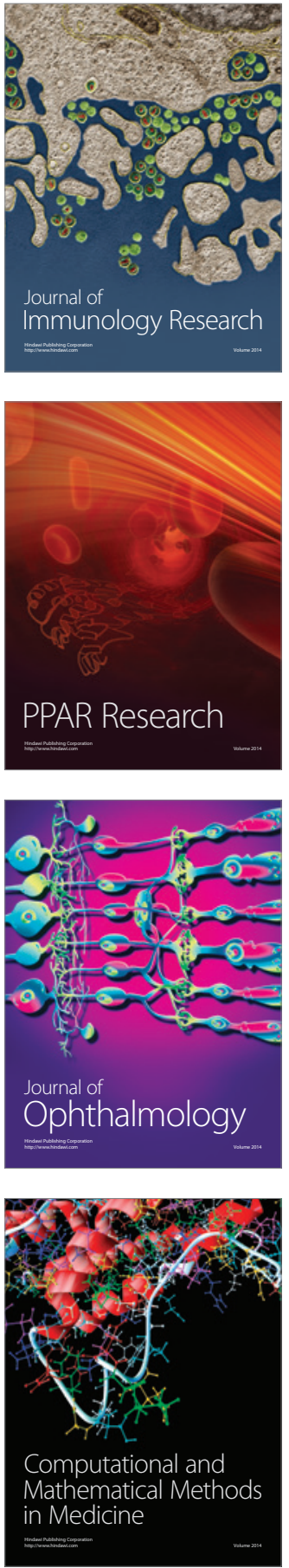

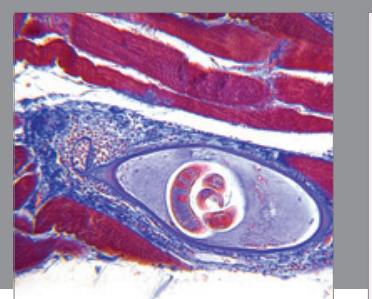

Gastroenterology Research and Practice

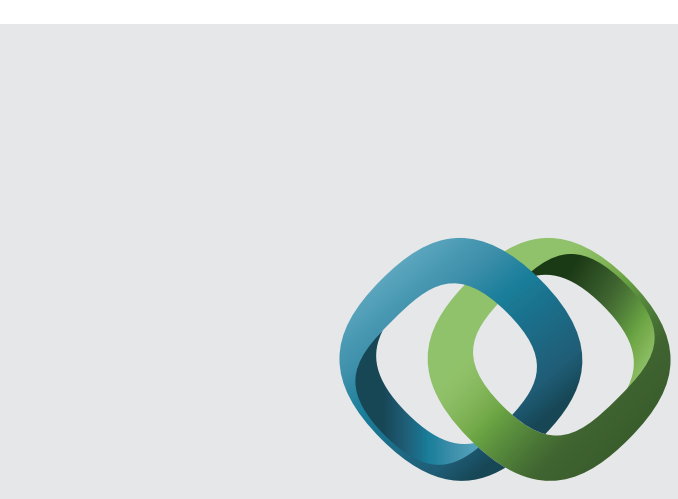

\section{Hindawi}

Submit your manuscripts at

http://www.hindawi.com
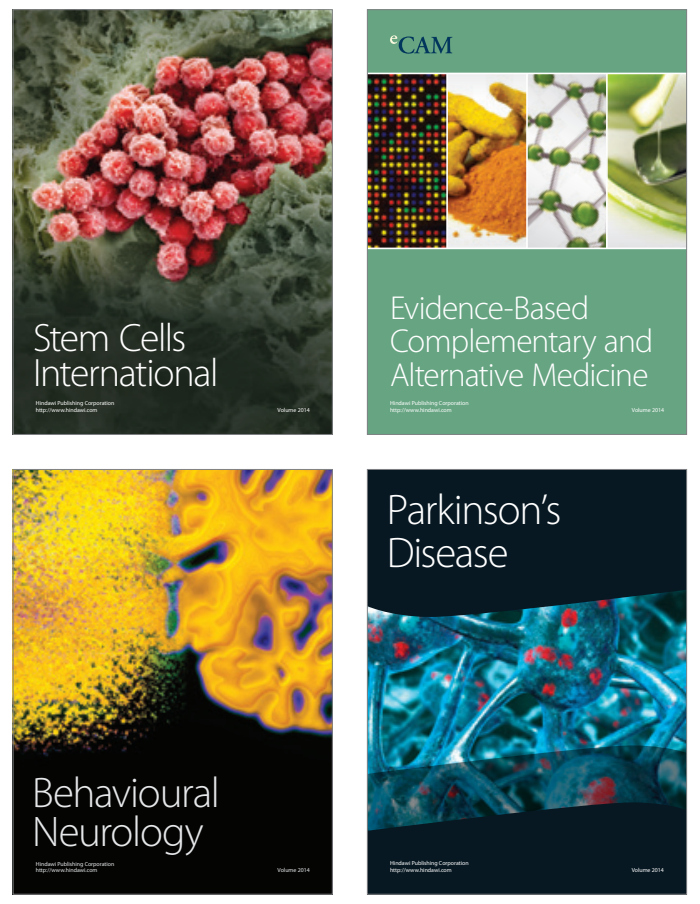
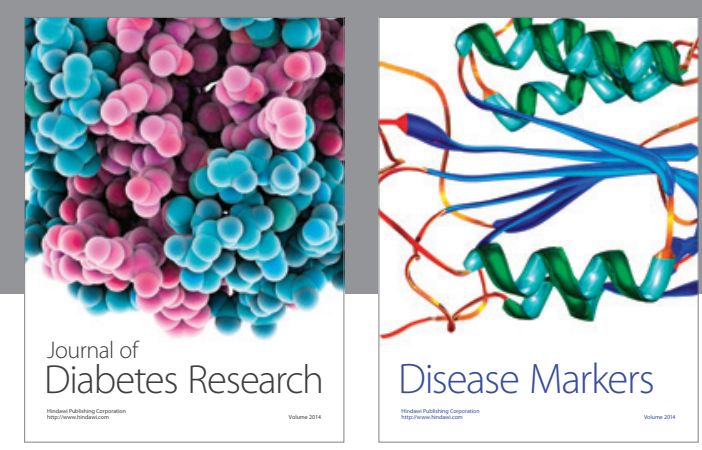

Disease Markers
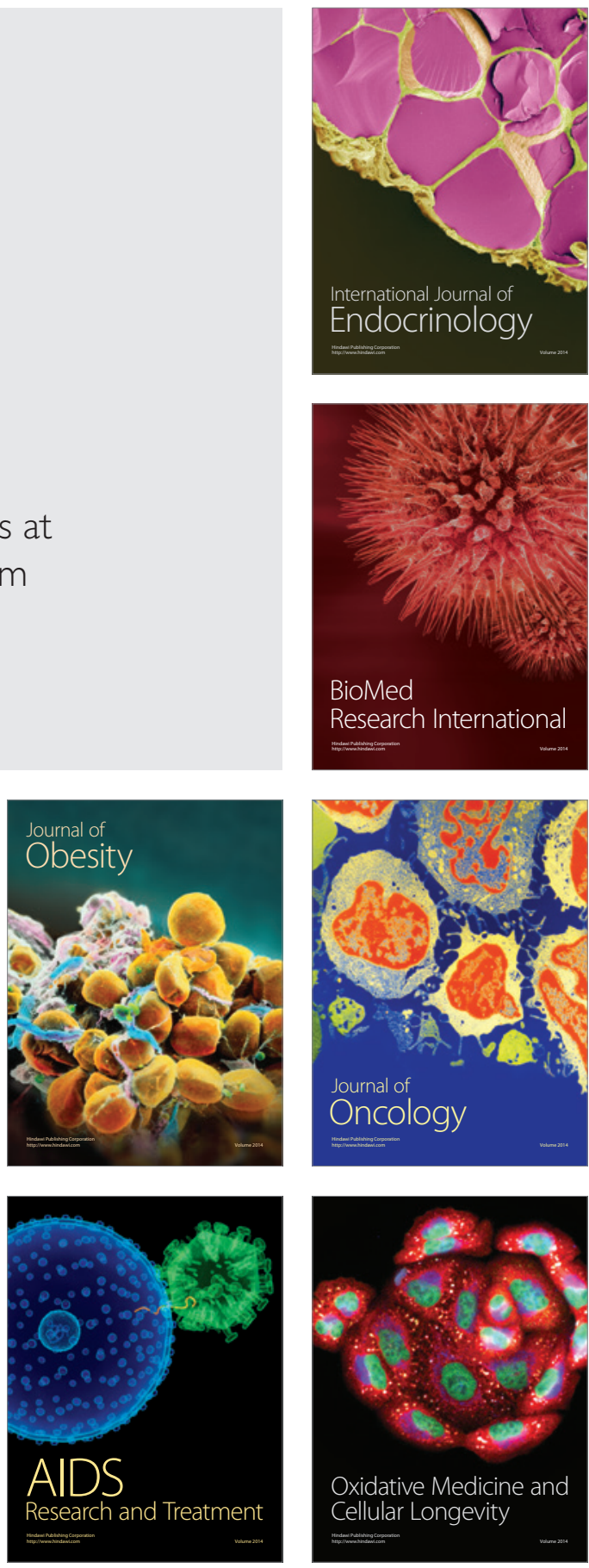